\title{
PROMOSI KESEHATAN TENTANG PEMBERIAN ASI EKSKLUSIF TERHADAP PENGETAHUAN DAN SIKAP IBU HAMIL
}

\author{
Rotua Sumihar Sitorus ${ }^{1}$, Kristina L. Silalahi ${ }^{2}$ \\ ${ }^{1,2}$ Fakultas Keperawatan dan Kebidanan Universitas Prima Indonesia \\ Email: rotuasumiharsitorus@unprimdn.ac.id; kristinasilalahi@unprimdn.ac.id
}

\begin{abstract}
Stunting is a disruption of physical development that has passed with decreasing in the growth rate of children. Puskesmas Pancur Batu conducts stunting prevention through health promotion to increase knowledge and attitudes of pregnant women about exclusive breastfeeding. The number of mothers giving exclusive breastfeeding only reached $44.9 \%$ (target $80 \%$ ). The purpose of the study was to analyze the effect of health promotions with leaflet media about exclusive breastfeeding on the knowledge and attitudes of pregnant women in stunting prevention. The study design was quasiexperimental with a sample of 40 pregnant women. The study was conducted in October 2019 in Puskesmas Pancur Batu. The sampling technique is done purposively. Data were analyzed using independent t test. The results showed that before the pre-test, the average score of knowledge variables from the intervention group 6.60 and the comparison group 6.22, after the post-tes increased to 10.30 and 8.34. The average score of attitude variables from the intervention group was 4.04 and the comparison group was 4.44, after the post-test increased to 5.80 and 4.84. The results of the statistic test showed that health promotion influences the knowledge and attitude of pregnant women in preventing stunting before and after the intervention with $p=0.005$ and $p 0.028<0.05$. It is recommended that Puskesmas staff conduct health promotion through the distribution of leaflets to facilitate pregnant women in understanding the benefits of exclusive breastfeeding in an effort to prevent stunting.
\end{abstract}

Keywords: promotion, exclusive breastfeeding, knowledge, attitude

\section{PENDAHULUAN}

Kehamilan merupakan masa kehidupan yang penting, pada masa ini ibu harus mempersiapkan diri sebaikbaiknya untuk menyambut kelahiran bayinya. Salah satu faktor yang berpengaruh terhadap kesehatan ibu selama hamil adalah perlu memperhatikan makanan sehari-hari agar terpenuhi zat gizi yang dibutuhkan (Manuaba, 2013).

Ibu juga memikul tanggung jawab yang lebih besar dalam mengasuh bayi sampai balita karena masa anak balita merupakan masa emas untuk perkembangan dan pertum-buhannya sehingga diperlukan asuhan gizi. Bila pertumbuhan bayi tidak optimal, maka anak dapat menyebabkan stunting (Proverawati \& Asfuah, 2014).

Sunting pada anak bawah 5 tahun di dunia pada 2018 sebanyak 149 juta dan 40 juta memiliki kelebihan berat badan (overweight) (WHO, 2018). Hasil Riskesdas Indonesia, prevalensi sangat pendek balita tahun 2013 yaitu 30,8\% mengalami peningkatan menjadi $37,2 \%$ tahun 2018. Pada tahun 2013 prevalensi 
pendek balita sebesar $18,0 \%$ mengalami penurunan tahun 2018 yaitu $11,5 \%$ (Kemenkes, 2018).

Salah satu penyebab anak mengalami stunting adalah riwayat pemberian ASI eksklusif. Faktor yang dapat menyebabkan stunting adalah pemberian Air Susu Ibu (ASI) yang salah bisa karena inisiasi yang terlambat, tidak ASI eksklusif, penghentian menyusui yang terlalu cepat (World Health Organization, 2014).

\section{Data World Health Organization} (WHO) dan United Nations Children's Fund (UNICEF) dan diketahui ibu-ibu di seluruh dunia yang menyusui bayinya berasal dari kelompok etnis Cina atau lainnya yaitu 97\%, etnis hitam yaitu 96\%, etnis Asia yaitu 95\%. Ibu-ibu yang berusia di atas 30 tahun yaitu $87 \%$ dan ibu usia di bawah 20 tahun hanya yaitu $58 \%$. Ibu yang tinggal di Inggris, Skotlandia, Wales dan Irlandia Utara memiliki tingkat menyusui terendah (WHO/ UNICEF, 2012).

Berdasarkan data SDKI didapatkan cakupan ASI Ekslusif pada bayi di bawah 6 bulan di Indonesia pada tahun 2007 yaitu $27 \%$ meningkat menjadi sebesar 42\% tahun 2013 (Kemenkes, 2014). Wilayah Provinsi Sumatera Utara cakupan ASI ekslusif juga masih rendah sebesar $41,3 \%$. Hasil yang didapatkan sangat jauh dari taget yaitu sebesar $85 \%$ (Kemenkes, 2013). Data dari Dinas
Kabupaten Deli Serdang tahun 2018 bahwa jumlah bayi yang mendapat ASI eksklusif adalah sebesar 47,04\%. Hal ini menunjukkan bahwa cakupan bayi yang mendapat ASI eksklusif sangat rendah dan belum mencapai target $80 \%$.

Manfaat ASI eksklusif bagi ibu adalah mencegah perdarahan pasca persalinan, mempercepat kembalinya rahim ke bentuk semula, mencegah anemia defisiensi zat besi, menunda kesuburan, mengurangi kemungkinan kanker payudara dan ovarium, menjalin kasih sayang antara ibu dengan bayi, mempercepat pemulihan kesehatan ibu dan lebih praktis karena ASI lebih mudah diberikan setiap saat, saat bayi membutuhkan serta rasanya bervariasi tergantung makanan yang dikonsumsi ibu (Proverawati \& Asfuah, 2014).

Tujuan promosi kesehatan sebagai berikut: 1) Menjadikan kesehatan sebagai sesuatu yang bernilai di masyarakat, 2) Menolong individu agar mampu secara mandiri atau kelompok mengadakan kegiatan untuk mencapai hidup sehat, dan 3) Mendorong penggunaan secara tepat sarana pelayanan kesehatan yang ada. Pemberian promosi kesehatan kepada seseorang lebih efektif bila menggunakan alat bantu media dalam bentuk gambar-gambar (leaflet) untuk memahami materi yang disampaikan dari pada metode ceramah tanpa media (Notoatmodjo, 2012). 
Hasil survei awal di Puskesmas Pancur Batu Kecamatan Pancur Batu Kabupaten Deli Serdang berdasarkan Laporan Kesehatan Ibu dan Anak (KIA) tahun 2018 bahwa jumlah bayi usia 0-6 bulan sebanyak 901 orang, diantaranya memberikan ASI Eksklusif sebanyak 405 orang $(44,9 \%)$, belum mencapai target 90\%. Ibu hamil belum sepenuhnya memberikan ASI Eksklusif kepada bayi usia 0-6 bulan diduga disebabkan promosi kesehatan belum efektif.

Cara untuk meningkatkan pengetahuan dan sikap ibu dalam pemberian ASI Ekslusif pada bayi usia 06 bulan perlu diberikan promosi kesehatan berupa leaflet. Hasil skor pengetahuan dan sikap tentang ASI eksklusif melalui pemberian leaflet (3 orang) dan tanpa leaflet (3 orang) memiliki perbedaan rata-rata yaitu 7,2 dan 5,6.
Kondisi mengindikasikan pemberian media leaflet lebih tinggi tingkat pengetahuan dan sikap tentang ASI Eksklusif.

\section{METODE}

Desain penelitian adalah quasieksperimen. Populasi adalah ibu hamil yang mengikuti Kelas Ibu Hamil sebanyak 40 orang dan seluruh dijadikan sampel penelitian dan dibagi menjadi 2 kelompok yaitu kelompok intervensi (20 orang) dan pembanding (20 orang). Teknik pengambilan sampel secara purposive sampling. Data dianalisis menggunakan uji independent $t$ test dengan asumsi data perdistribusi normal.

\section{HASIL DAN PEMBAHASAN}

Hasil analisis univariat dan bivariat disajikan sebagai berikut.

\section{Analisis Univariat}

Tabel 1. Karakteristik Ibu Hamil

\begin{tabular}{|c|c|c|c|c|}
\hline \multirow{2}{*}{ Karakteristik } & \multicolumn{2}{|c|}{ Kelompok Intervensi } & \multicolumn{2}{|c|}{ Kelompok Pembanding } \\
\hline & $\mathbf{n}$ & $\%$ & $\mathbf{n}$ & $\%$ \\
\hline \multicolumn{5}{|l|}{ Umur } \\
\hline$<20$ tahun & 1 & 5,0 & 1 & 5,0 \\
\hline 20-35 tahun & 17 & 85,0 & 18 & 90,0 \\
\hline$>35$ tahun & 2 & 10,0 & 1 & 5,0 \\
\hline \multicolumn{5}{|l|}{ Pendidikan } \\
\hline SD & 1 & 5,0 & 0 & 0,0 \\
\hline SMP & 6 & 30,0 & 9 & 45,0 \\
\hline SMA & 11 & 55,0 & 10 & 50,0 \\
\hline Perguruan Tinggi & 2 & 10,0 & 1 & 5,0 \\
\hline \multicolumn{5}{|l|}{ Pekerjaan } \\
\hline IRT & 14 & 70,0 & 15 & 85,0 \\
\hline Wiraswasta & 4 & 20,0 & 4 & 20,0 \\
\hline Pegawai & 2 & 10,0 & 1 & 5,0 \\
\hline \multicolumn{5}{|l|}{ Paritas } \\
\hline Primipara (1 org) & 4 & 20,0 & 1 & 5,0 \\
\hline Multipara (2-5 org) & 15 & 75,0 & 17 & 85,0 \\
\hline $\begin{array}{l}\text { Grandemultipara } \\
(>5 \text { org) }\end{array}$ & 1 & 5,0 & 2 & 10,0 \\
\hline
\end{tabular}


Tabel 2. Distribusi Frekuensi Pengetahuan dan Sikap Ibu Hamil

\begin{tabular}{|c|c|c|c|c|c|c|c|c|}
\hline & \multicolumn{4}{|c|}{ Pre Test } & \multicolumn{4}{|c|}{ Post Test } \\
\hline & \multicolumn{2}{|c|}{$\begin{array}{l}\text { Kelompok } \\
\text { Intervensi }\end{array}$} & \multicolumn{2}{|c|}{$\begin{array}{c}\text { Kelompok } \\
\text { Pembanding }\end{array}$} & \multicolumn{2}{|c|}{$\begin{array}{l}\text { Kelompok } \\
\text { Intervensi }\end{array}$} & \multicolumn{2}{|c|}{$\begin{array}{l}\text { Kelompok } \\
\text { Pembanding }\end{array}$} \\
\hline & $\mathbf{n}$ & $\%$ & $\mathbf{n}$ & $\%$ & $\mathbf{n}$ & $\%$ & $\mathbf{n}$ & $\%$ \\
\hline \multicolumn{9}{|c|}{ Pengetahuan } \\
\hline Baik & 4 & 20,0 & 5 & 25,0 & 8 & 40,0 & 6 & 30,0 \\
\hline Cukup & 8 & 40,0 & 5 & 25,0 & 7 & 35,0 & 9 & 45,0 \\
\hline Kurang & 8 & 40,0 & 10 & 50,0 & 5 & 25,0 & 5 & 25,0 \\
\hline \multicolumn{9}{|l|}{ Sikap } \\
\hline Positif & 9 & 45,0 & 9 & 45,0 & 14 & 70,0 & 11 & 55,0 \\
\hline Negatif & 11 & 55,0 & 11 & 55,0 & 6 & 30,0 & 9 & 45,0 \\
\hline
\end{tabular}

\section{Analisis Bivariat}

Sebelum melakukan uji statistik tersebut, peneliti terlebih dahulu melakukan uji persyaratan normalitas data menggunakan uji One-Sample
Kolmogorov-Smirnov Test. Hasil uji diperoleh nilai $\mathrm{p}$ sebesar 0,200 dan 0,129 lebih besar dari 0,05 , artinya data penelitian yaitu pengetahuan dan sikap diasumsikan berdistribusi normal.

Tabel 3. Pengetahuan Sebelum dan Sesudah Intervensi

\begin{tabular}{lccc}
\hline Variabel & & Mean + SD & $p$ \\
\hline $\begin{array}{l}\text { Pengetahuan kelompok } \\
\text { intevensi }\end{array}$ & Pre test & $6,60+3,097$ & 0,664 \\
$\begin{array}{l}\text { Pengetahuan kelompok } \\
\text { pembanding }\end{array}$ & $6,22+3,485$ & \\
$\begin{array}{l}\text { Pengetahuan kelompok } \\
\text { intevensi }\end{array}$ & & \\
$\begin{array}{l}\text { Pengetahuan kelompok } \\
\text { pembanding }\end{array}$ & Post test & $10,30+2,415$ & 0,005 \\
\hline
\end{tabular}

Hasil penelitian menunjukkan ratarata skor pengetahuan kelompok intervensi dan pembanding (pre test) sebesar 6,60 dan 6,22, meningkatkan sesudah intervensi (post test) menjadi 10,30 dan 8,34 .

Tabel 4. Sikap Sebelum dan Sesudah Intervensi

\begin{tabular}{lccc}
\hline Variabel & & Mean $+\boldsymbol{S D}$ & $\boldsymbol{p}$ \\
\hline Sikap kelompok intevensi & \multirow{2}{*}{ Pre test } & $4,04 \pm 2,368$ & 0,440 \\
Sikap kelompok pembanding & & $4,44 \pm 1,791$ & \\
Sikap kelompok intevensi & \multirow{2}{*}{ Post test } & $5,80 \pm 1,619$ & \multirow{2}{*}{0,028} \\
Sikap kelompok pembanding & & $4,84 \pm 1,146$ & \\
\hline
\end{tabular}

Rata-rata skor sikap kelompok intervensi dan pembanding (pre-test) sebesar 4,04 dan 4,44, meningkatkan sesudah intervensi (post-test) menjadi 5,80 dan 4,84 .
Hasil analisis bivariat diperoleh nilai p $0,005<0,05$, artinya ada pengaruh promosi kesehatan terhadap pengetahuan responden tentang pem-berian ASI Eksklusif sesudah diberikan intervensi. Demikian juga nilai $p$ sikap yaitu 
$0,028<0,05$, artinya ada pengaruh promosi kesehatan terhadap sikap responden tentang pemberian ASI Eksklusif sesudah diberikan intervensi.

Setelah diuraikan hasil penelitian, maka selanjutnya dianalisis sebagai berikut: Ada perbedaan rata-rata pengetahuan ibu hamil antara kelompok intervensi dengan pem-banding sesudah dilakukan promosi kesehatan (post test), dimana pengetahuan ibu hamil kelompok intervensi adalah 10,30 dan kelompok pembanding adalah 8,34. Terbukti dari nilai uji statistik ditunjukkan dengan nilai $\mathrm{p}<0,005$, artinya ada pengaruh promosi kesehatan terhadap pengetahuan ibu hamil tentang pemberian ASI Eksklusif dalam pencegahan stunting sebelum dan sesudah promosi kesehatan.

Sejalan dengan penelitian Widha Ayu Rima Merdhika, dan Mardji (2014) mengatakan bahwa terdapat pengaruh penyuluhan terhadap tingkat pengetahun dan sikap ibu menyusui dalam pemberian ASI eksklusif di Kecamatan Kanigoro Kabupaten Blitar. Selain itu, diketahui pula perbedaan tingkat pengetahuan dan sikap ibu tentang ASI eksklusif antara ibu yang diberi penyuluhan dengan metode buku saku, ibu yang diberi penyuluhan dengan metode simulasi lebih efektif dalam meningkatkan pengetahuan dan sikap ibu menyusui daripada ibu yang diberi penyuluhan tanpa diberi metode apa pun.
Promosi kesehatan menggunakan leaflet merupakan suatu proses dalam memberikan berbagai informasi kepada ibu hamil terutama tentang pemberian ASI Eksklusif pada bayi usia 0-6 bulan untuk mengoptimalkan pertumbuhan dan perkembangannya sehingga pada masa balita tidak mengalami stunting.

Sesuai dengan pendapat Setiana (2010) mengatakan keuntungan menggunakan media ini antara lain: sasaran dapat menyesuaikan dan belajar mandiri serta praktis karena mengurangi kebutuhan mencatat, sasaran dapat melihat isinya disaat santai dan sangat ekonomis, berbagai informasi dapat diberikan atau dibaca oleh anggota kelompok sasaran, sehingga bisa didiskusikan, dapat memberikan informasi yang detail yang mana tidak diberikan secara lisan, mudah dibuat, diperbanyak dan diperbaiki serta mudah disesuaikan dengan kelompok sasaran.

Selanjutnya hasil analisis bivariat menunjukkan bahwa ada perbedaan ratarata sikap ibu hamil antara kelompok intervensi dengan pembanding sesudah dilakukan promosi kesehatan (post-test), dimana sikap ibu hamil kelompok intervensi adalah 5,80 dan kelompok pembanding adalah 4,84. Terbukti dari nilai uji statistik ditunjukkan dengan nilai $\mathrm{p}<0,05$, artinya ada pengaruh promosi kesehatan terhadap sikap ibu hamil tentang pemberian ASI Eksklusif dalam 
pencegahan stunting sebelum dan sesudah promosi kesehatan.

Penyuluhan sebagai upaya promosi kesehatan untuk memberikan pengaruh terhadap sikap ibu dalam memberikan ASI Eksklusif. Sejalan dengan penelitian Triwibowo dan Pusphandani (2018) mengatakan sikap ibu hamil sebelum dilakukan penyuluhan kesehatan ibu bersikap positif $48.5 \%$ dan setelah diberi intervensi sikap positif menjadi $87.9 \%$ di di Posyandu Cempaka II Puskesmas Pembantu Kwala Bekala Medan.

Penelitian Suryani et al., (2019) menjelaskan peningkatan rata-rata pengetahuan dari 84.46 hingga 92.14, sikap dari 31.61 hingga 33.96 dan praktik menyusui dari 69,76 hingga 83,81 setelah diberikan penyuluhan. Ada pengaruh dari penyuluhan tentang pengetahuan, sikap dan praktik menyusui setelah dilakukan penyuluhan dengan frekuensi lima kali setiap bulan selama lima bulan menggunakan leaflet di Puskesmas Sawah Lebar Kota Bengkulu.

Menurut Asfaw, Argaw, dan Kefene (2015) melakukan intervensi dalam penelitian berupa pemberian konseling tentang pemberian makanan bayi kepada ibu, di mana peluang ibu yang tidak menerima konseling tentang pemberian maka-nan bayi sebesar 0,42 kali lebih kecil kemungkinannya untuk memberikan ASI Eksklusif dibandingkan mereka yang menerima layanan konseling di Debre Berhan Ethiopia Tengah.

Besarnya manfaat promosi kesehatan yang diberikan sangat mempengaruhi pengetahuan dan sikap ibu hamil terhadap pemberian ASI Eksklusif dalam pencegahan stunting, sehingga perlu di masa mendatang kegiatan promosi kesehatan dilakukan secara kontinu di wilayah kerja Puskesmas Pancru Baru agar ibu hamil memiliki niat yang kuat memberikan ASI Eksklusif dalam pencegahan stunting dan gizi balita sangat pendek atau pendek.

\section{KESIMPULAN DAN SARAN}

Secara statistik terbukti bahwa ada perbedaan rata-rata pengetahuan dan sikap ibu hamil tentang ASI Eksklusif dalam pencegahan stunting yang signifikan sesudah diberikan intervensi berupa promosi kesehatan. Disarankan petugas Puskesmas memberikan penyuluhan secara berkala menggunakan lealfet atau alat bantu promosi kesehatan lainnya untuk mempermudah ibu hamil dalam memahami manfaat pemberian ASI Eksklusif.

\section{DAFTAR PUSTAKA}

Asfaw, M. M., Argaw, M. D., \& Kefene, Z. K. (2015). Factors associated with exclusive breastfeeding practices in Debre Berhan District, Central Ethiopia: A cross sectional community based study. International Breastfeeding Journal, $\quad$ 10(1), 1-9. 
https://doi.org/10.1186/s13006-0150049-2.

Kemenkes. (2013). Riset Kesehatan Dasar. Jakarta: Badan Penelitian dan Pengembangan Kesehatan Kementerian Kesehatan RI.

Kemenkes. (2014). Situasi dan Analisis ASI Eksklusif. Pekan ASI Internasional. Pusat Data Informasi Kementerian Kesehatan RI. Jakarta: Kemenkes RI.

Kemenkes. (2018). Hasil Utama Riskesdas Tahun 2018. Jakarta: Kemenkes RI, Badan Penelitian dan Pengembangan Kesehatan.

Manuaba, I. (2013). Pengantar Kuliah Obstetri. Jakarta: EGC.

Notoatmodjo, S. (2012). Promosi Kesehatan dan Ilmu Perilaku. Jakarta. Jakarta: PT Rineka Cipta.

Proverawati, A., \& Asfuah. S. (2014). Buku Azar Gizi Untuk Kebidanan. Yogyakarta: Nuha Medica.

Setiana, L. (2010). Teknik Penyuluhan dan Pemberdayaan Masyarakat. Bogor: Pustaka Wirausaha Muda.

Suryani, D., Kusdalinah, Jumiyati, Yandrizal, Anggraini, W., \& Agustina P, B. (2019). The Effect Of Counseling On Knowledge, Attitudes, And Practices Of Mothers breastfeeding In The Work Area Of Sawah Lebar Community Health Center, Bengkulu 2017. 14(Icihc). https://doi.org/10.2991/icihc18.2019.43.

Triwibowo, C., \& Pusphandani, M. E. (2018). Kesehatan Lingkungan dan K3. Yogyakarta: Nuha Medical.

WHO/UNICEF. (2012). Global Nutrion Target 2025.Breastfeeding Policy Brief.WHO/MNH/NHD 14.7.

WHO. (2018). Global Health Observatory (GHO) Data: Child Malnutrition. Retrieved from https://www.who.int/gho/childmalnutrition/en/.

Widha Ayu Rima Merdhika, Mardji, M. D. (2014). Pengaruh penyuluhan asi eksklusif terhadap pengetahuan ibu tentang asi eksklusif dan sikap ibu menyusui di kecamatan kanigoro kabupaten blitar. Teknologi Dan
Kejuruan, 37(1), 65-72.

World Health Organization. (2014). Childhood Stunting: Challenges and opportunities. Report of a Promoting Healthy Growth and Preventing Childhood Stunting colloquium. In WHO Geneva. 